\title{
The Influence of Cyber Informatics as Stable Archetypes on Networking
}

\author{
P. Arumugam, T. Krishna Kumar
}

\begin{abstract}
In this day and age, the quantity of occupants in city and number of vehicles out on the town are extending step by step. With growing in the urban masses and therefore the amount of vehicles, need of controlling paths, thoroughfares and lanes was transformed into a significant issue. The present traffic structure has no complement on live traffic circumstance, which prompts inefficient traffic the administrators frameworks. This endeavor has been realized by using the propelled picture taking care of technique using Mat lab programming and it means to turn away overpowering traffic stop up. Moreover, for executing this endeavor we used the automated Image dealing with procedure. A CCTV is placed in a busy time gridlock way that will catch pictures in a gathering method for the road and the vehicles on where we have to control traffic by using these CCTV pictures are incredible to keep on knowing the traffic thickness. According to the readied data from picture dealing with, the controller sends the solicitation to the traffic LED's to show explicit time on the banner to administer traffic.LED's to demonstrate specific time on the flag to oversee traffic.
\end{abstract}

Index Terms-Traffic signal lights, Digital Image Processing, edge de-tection.

\section{INTRODUCTION}

In present day life, traffic blockage turned into a difficult issue and is turning into a hindrance step by step. The expanding number of vehicles as well as insufficient foundation alongside the outlandish spread of the improvement are central purposes behind extended car over-burden. The significant reason for automobile overload is the enormous number of vehicles present essentially in the metropolitan urban communities which happened because of increment in populace and the extension of city limits. To determine this issue, the specialists should eagerly ask people to use open vehicle, for instance, transports or vehicles with minimal size, for instance, bicycles or increment tax assessment on close to home vehicles which keeps a beware of number of individual vehicles. Particularly, in a couple of Asian countries, for instance, Vietnam, the close by government specialists passed law limiting the amount of vehicles which can be had for a family. The techniques referenced above are proficient yet not absolutely prudent. The inadequate system especially at the street crossing points can't manage the traffic which is in like manner a

Revised Manuscript Received on December 11, 2019

* Correspondence Author

P. Arumugam, Research Scholar, Department of CSE, Bharath Institute of Higher Education and Research, Chennai, Tamilnadu, India.

Dr.T. Krishna Kumar, Professor, Department of CSE, Bharath Institute of Higher Education and Research, Chennai, Tamilnadu, India. fundamental explanation. Despite the fact that, the open vehicle administrations are accessible,there are unacceptable, mostly in different creating nations. Likewise, the expressway and boulevards are unfit and inadequate of meeting the central essential of extending number of vehicles. As opposed to wearing down roads to suit the creating traffic, various frameworks have been imagined to lessen the traffic on boulevards like embeddings installed controllers. Be that as it may, the traffic control framework at the sign intersection was not effective till the previous decade. The traffic the board utilizing picture preparing is one of the methods to deal with the traffic at the sign intersection. This procedure is quickly characterized in this paper.

\section{RELATED WORKS}

This area gives clarification about different methodologies of traffic control framework. In past works they manage distinctive calculation innovations and gear's for traffic control at the sign intersections.

With reference to article 8 by Prasanth Jadhav distributed in 2016, a PC vision framework is created to check vehicles proceeding onward streets. The traffic sign are enlisted to the controller unit with the assistance of sensors and the progression of traffic for the given timespan and spot is broke down. The second piece of this task is the sign portrayal head given to guarantee unidirectional traffic stream. This framework recognizes the entering items to the scene and tracks them all through the video.

With reference to the article 7 by Kavya $\mathrm{P}$ Walad distributed in 2014, a Gradient based which is additionally called first request edge discovery and Laplacian based as second request edge recognition activities are exhibited and depicted in this paper. Despite the fact that this framework is superior to anything some other past frameworks utilized, there are such huge numbers of downsides with Gaussian-based edge location is powerless to commotion. A progressively viable edge identification calculation is required to give a blunder less arrangement which can give a superior yield. With reference to the article 10 by Varsha Sahadev Nagmode from Pune, in the plan of systems of ultrasonic sensors arranged gaining ground toward screen traffic levels. The road sensors are distinguishing vehicles and find the component of traffic in that way. Such measurements are low, medium and high that are mounted at the particular division discrete.

\section{Published By:}

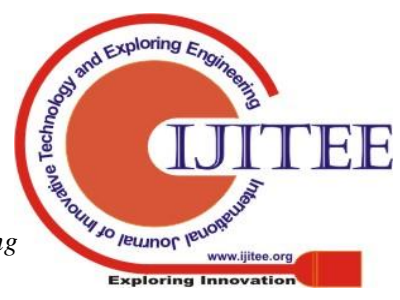


The recognized data is constant and is sent to the controller to recognize traffic levels. If the traffic level is high, by then the controller controls the synchronization of the banner in that way and gives greater chance to go to the vehicles. In case a low traffic level is recognized, by then control of the control movement in that way gives less time to pass a vehicle. Thusly, this structure offers need to the emergency vehicle at an unusual condition of traffic. The controller talks with the need structure through RF handsets.But this framework is progressively costly and it requires high

With reference to article 6,the seeing of the ordinariness of the data of each IoT contraption relies upon its data configuration given by the OM server. The watching center with the data structures instructs the OM server simply the data past the normal range instead of sending all of the data to the OM server.

With reference to article 3,a couple of astute traffic the administrators systems were explored. These fuse the use of RFID perusers and names, Green Wave systems, PDAs and remote correspondence with the Big Data center.

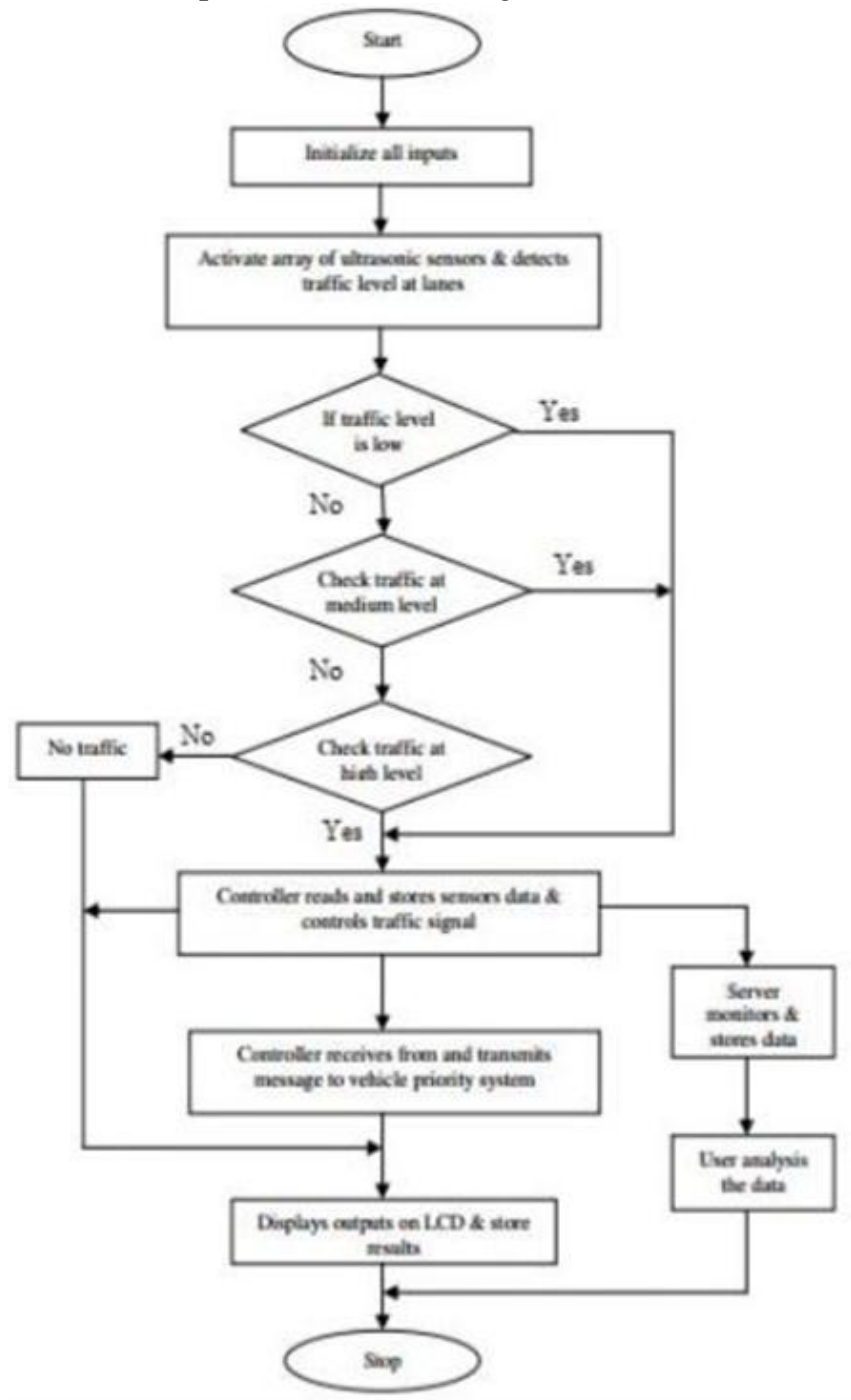

The IoT framework has been used to assemble data related traffic stop up even more quickly and decisively. Likewise, the adaptable application was inspected as a "UI" to recognize traffic stop up in different regions and outfit customers with elective courses. The objective of these establishment costs.

procedures is to outfit vehicle drivers with more information about traffic and road conditions. Besides, the requirement for emergency vehicles can be selected through shrewd traffic systems.

Hence, this survey work proves that traffic control system with Image Processing which implements Canny's Edge Detection algorithm is the best approach for using in present days.

\section{SYSTEM ANALYSIS}

In this project, we are using Arduino Board which is connected to the camera module to capture images of the empty road and then the pictures of the road with vehicles is also captured thus obtaining the density of the vehicles in the given lane.

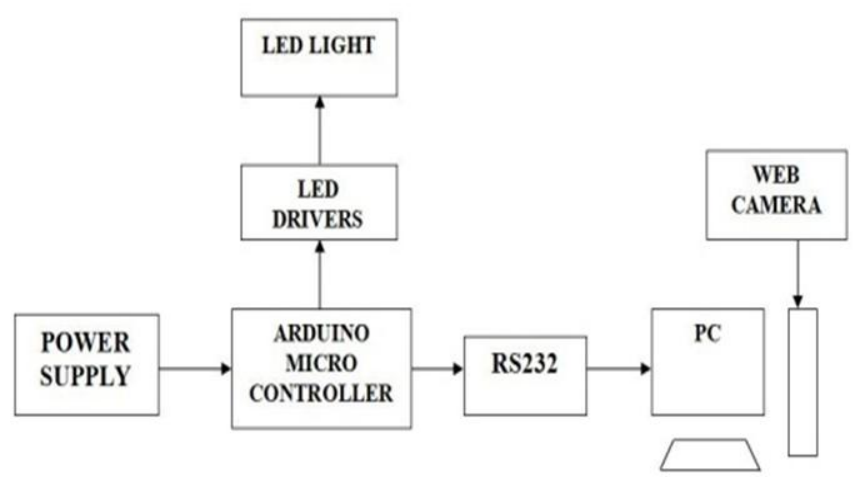

Figure 3.1: System analysis of the system

\section{EXISTING SYSTEM}

\section{Traditional Traffic Control Systems: Manual or Man Control:}

Physical controlling the name itself prescribes that human work is required to lessen the traffic. Taking nation's populace and the administration specialists into thought, a specific number of police are appointed for an endorsed intersection or specific area to lessen traffic. The traffic guidelines uses sign board which demonstrates to stop or go, sign light to control traffic. This framework is these days utilized in places where there is extremely less measure of traffic.

\section{Auto Regulating or Self Regulating:}

Programmed traffic light is controlled with the assistance of clock-timers and electrical sensors. The lights operate on a timer basis. This casing utilizes electrical sensors to catch the availability of the vehicle and the banner at each stage, and depending on the banner, the lights are turned on and off automatically.

\section{PitFallo OF EXISTING SYSTEM:}

In the human controlling system, we need human labor to get the work done. As we have traffic police in lesser in number compared to the required number, we cannot control traffic manually. 
In addition to this, man made mistakes might sometimes lead to serious accidents. Hence, a better solution to control traffic is required. On the other side, automatic traffic controlling requires timer for every phase which increases the static traffic which leads to increasing the pollution in the specific area. Utilizing electronic sensors is another route so as to recognize vehicles but the time is being wasted by a green light on an empty road. All these drawbacks are to be minimized to greater extent possible.

In the existing system, a manual switching is performed through a timing circuit. A person is present at the switching

station which is located at the middle of the junction and a static time circuit is fixed to each road phase thus giving Red (R), Yellow(Y),Green(G ).

The proposed framework configuration actualized in two sections, first is the vehicle checking and control unit and the second is the vehicle's need unit. Prior to the model execution, all segments and gadgets are tried.

Part of control and checking of the vehicle. In this part, the ARM controller connects with ultrasonic sensors, console, Wi-Fi module, LCD screen, LED and RF flag. Priority part of the vehicle In this part, the PIC microcontroller is interconnected with the RF handset, the console and the LCD screen.

\section{Disadvantages}

1. Requires man power

2. Usage of timers for every phase which ultimately leads to traffic congestion

3. Time wastage due to allocation of equal time to each phase.

\section{PROPOSED SYSTEM}

In this task, we fuse picture handling to control traffic at the intersection level. These days, the majority of the picture preparing strategies are being created to upgrade the pictures acquired from different sources, for example, rockets, military flights and so forth.

Picture preparing incorporates issues related to picture portrayal, different complex estimations and other weight frameworks which can be performed on the image data. The activity incorporates honing, lighting up, obscuring. In this undertaking, these tasks are performed on the pictures acquired through an advanced camera.

In this proposed framework, two arrangements of pictures were taken for a similar street. One lot of pictures contains every one of the paths that are vacant and the other arrangement of pictures are the paths which has certain measure of traffic. Here the pictures taken in shading are changed over to greyscale. After the pictures are changed over, the pictures are resized by the co-ordinates and improved. By the utilization of edge recognition calculations, the edges are furnished with limits and pictures are coordinated with one another and time is dispensed to each branch.
In the proposed methodology, once the pictures are captured, the image subtraction is performed on the image with vehicles with reference to the image with the empty road. Once the image subtraction is performed, the images are transformed into grayscale images and then to $\mathrm{b} / \mathrm{w}$. This step is performed to fill the holes obtained in the RGB to black and white conversion. It checks for the holes and if are no holes present, the density of the vehicles in the lanes is calculated and the timers are prioritized for each lane according to the density of traffic present in that lane.

\section{METHODOLOGY}

\section{Image Acquisition:}

The pictures are for the most part in type of a two-dimensional capacity $\mathrm{f}(\mathrm{x}, \mathrm{y})$. The ampleness of picture at some arbitrary point is called power of the photos. The components $\mathrm{x}$ and $\mathrm{y}$ should be changed over into restricted discrete characteristics to outline a propelled picture. Each automated picture is included a restricted segment and each constrained part is named pixel.

\section{Formation of Image:}

There are not many conditions for forming an image $\mathrm{f}(\mathrm{x}, \mathrm{y})$ as estimations of picture are comparing to imperativeness radiated by a physical source. So $f(x, y)$ must be non-zero and limited.

\section{Image Pre-Processing:}

The pictures are for the most part in type of a two-dimensional capacity $\mathrm{f}(\mathrm{x}, \mathrm{y})$. The ampleness of picture at some arbitrary point is called power of the photos. The components $\mathrm{x}$ and $\mathrm{y}$ should be changed over into restricted discrete characteristics to outline a propelled picture. Each automated picture is included a restricted segment and each constrained part is named pixel.

\section{Formation of Image:}

There are not many conditions for forming an mage $f(x, y)$ as estimations of picture are comparing to imperativeness radiated by a physical source. So $\mathrm{f}(\mathrm{x}, \mathrm{y})$ must be non-zero and limited.

\section{RESULTS AND DISCUSSION}

\section{A. IMAGE ENHANCEMENT}

Image enhancement method for modifying advanced pictures with the end goal that the outcomes are increasingly able for showcase or investigation or analysis. For example, the key characteristics can be identified by eliminating noise.

In pictures with poor differentiation, the adjoining characters converge amid binarization. Thus, the speed of the characters needs to be reduced before applying threshold to it's word image. Therefore, the concept of "POWER-LAW TRANSFORMATION" is introduced to increase the dissimilarity of

\section{Published By:}




\section{The Influence of Cyber Informatics as Stable Archetypes on Networking}

the characters which results in better segmentation. The rudimentary type of power law change is

$\mathrm{s}=\left(\mathrm{c}^{*} \mathrm{r}\right) \gamma, \quad \mathrm{r}=$ input intensities $\mathrm{s}=$ output intensities

$\mathrm{c}=$ positive constant $\quad \gamma=$ positive

constants.

Various kinds of devices are used for printing, image capture and display response as stated in power-law. By tradition, the exponent utilized in the power-law condition is called gamma. Therefore, the process used to redress these power-law reaction marvels is called gamma correction. Gamma rectification is compulsory, if showing a picture kinds of devices are used for printing, image capture and display response as stated in power-law. By tradition, the exponent utilized in the power-law condition is called gamma.Therefore, the process used to redress these power-law reaction marvels is called gamma correction. Gamma rectification is compulsory, if showing a picture precisely on a PC screen. In our experimentation, $\gamma$ is fluctuated from 1 to 5 .. If $c \neq 1$, then the pixel range values will be significantly affected by scaling. Along these lines, to keep away from another phase of rescaling after the transformation of the power law, we reset the estimation of $\mathrm{c}$ to 1 . With $\gamma=1$ and the changed picture of the power law goes through the binarization, there will be no adjustments in the outcome the outcome will be equivalent to in straightforward binarization. At the point when $\gamma>1$, an adjustment in the histogram diagram happens, since there is a variance in tests in the compartments towards the dark estimation of zero. Gamma redress is fundamental in situations where the picture is shown on a PC screen.

\section{Canny's Edge Detection}

The Canny's Edge Detector is usually used picture taking care of contraptions for perceiving edges. It is a multi-step process, which can be executed on the GPU as a course of action of channels. Vigilant edge discovery methodology has three goals.

\section{Low blunder rate: -}

All edges should be found, and there should be no false or invalid responses. i.e, the edges must be nearer to the primary edges.

\section{Edge point should be especially bound: -}

The edges found must be found closer to genuine edges. for example, the division between a point set apart as an edge by the pioneer and the purpose of assembly of the chief edge ought to be least.

\section{B. Single EDGE POINT REACTION: -}

The finder must return just a solitary point for each obvious edge point i.e.:, the quantity of neighborhood maxima around the genuine edge should be least. This suggests the locator must not recognize distinctive edge pixels where just a single lone edge point exists.

$$
\mathrm{e}=\text { eccentricity } \mathrm{g}(\mathrm{x}, \mathrm{y})=\text { weight } \text { of grayscale }
$$

\section{ADVANTAGES:}

Time is varying according to the density

Longer wait times are not needed

Traffic density at each road is identified by a single camera

All the lanes were individually tested and later were integrated into a single main module. The images of the empty road which are taken by the web cam are compared with images which contains the traffic. Each image obtained is translated into grayscale and the traffic density is calculated. The Arduino board receives the signal and timer is allocated to each phase present in the junction depending upon the traffic density. If any vehicle such as ambulance is present in the lane, it is given a higher priority.

\section{CONCLUSION}

In this proposed rush hour gridlock decrease framework which utilizes picture handling systems, another period of traffic the executives which diminishes the traffic blockage and time delay for the individuals. This technique don't require any people for control and upkeep of the traffic. It utilizes effective edge location calculations to recognize traffic and thus it limits the downsides in the current framework. Likewise, it additionally gives an office to go to the crisis vehicles, for example, rescue vehicle and give robotized higher priority or need to it.

\section{REFERENCES}

1. Kumaravel A., Meetei O.N.,An application of non-uniform cellula automata for efficient cryptography,2013 IEEE Conference on Information and Communication Technologies, ICT 2013,V-,I-,PP-1200-1205,Y-2013

2. Kumarave A., Rangarajan K.,Routing alogrithm over semi-regula tessellations,2013 IEEE Conference on Information and Communication Technologies, ICT 2013,V-,I-,PP-1180-1184,Y-2013

3. Dutta P., Kumaravel A.,A novel approach to trust based identification of leaders in social networks,Indian Journal of Science and Technology,V-9,I-10,PP--,Y-2016

4. Kumaravel A., Dutta P.,Application of Pca for context selection for collaborative filtering,Middle - East Journal of Scientific Research,V-20,I-1,PP-88-93,Y-2014

5. Kumaravel A., Rangarajan K.,Constructing an automaton for exploring dynamic labyrinths,2012 International Conference on Radar, Communication and Computing, ICRCC 2012,V-,I-,PP-161-165,Y-2012

6. Kumaravel A.,Comparison of two multi-classification approaches for detecting network attacks,World Applied Sciences Journal,V-27,I-11,PP-1461-1465,Y-2013

7. Tariq J., Kumaravel A.,Construction of cellular automata over hexagonal and triangular tessellations for path planning of multi-robots,2016 IEEE International Conference on Computational Intelligence and Computing Research, ICCIC 2016,V-,I-,PP--,Y-2017

8. Sudha M., Kumaravel A.,Analysis and measurement of wave guides using poisson method,Indonesian Journal of Electrical Engineering and Computer Science, V-8,I-2,PP-546-548,Y-2017

9. Ayyappan G., Nalini C., Kumaravel A.,Various approaches of knowledge transfer in academic social network,International Journal of Engineering and Technology,V-,I-,PP-2791-2794,Y-2017 
10. Kaliyamurthie, K.P., Sivaraman, K., Ramesh, S. Imposing patient data privacy in wireless medical sensor networks through homomorphic cryptosystems 2016, Journal of Chemical and Pharmaceutical Sciences

11. Kaliyamurthie, K.P., Balasubramanian, P.C. An approach to multi secure to historical malformed documents using integer ripple transfiguration 2016 Journal of Chemical and Pharmaceutical Sciences 9

12. A.Sangeetha,C.Nalini,"Semantic Ranking based on keywords extractions in the web", International Journal of Engineering \& Technology, 7 (2.6) (2018) 290-292

13. S.V.GayathiriDevi,C.Nalini,N.Kumar,"An efficient software verification using multi-layered software verification tool "International Journal of Engineering \& Technology, 7(2.21)2018 454-457

14. C.Nalini,ShwtambariKharabe,"A Comparative Study On Different Techniques Used For Finger - Vein Authentication", International Journal Of Pure And Applied Mathematics, Volume 116 No. 82017 , 327-333, Issn: 1314-3395

15. M.S. Vivekanandan and Dr. C. Rajabhushanam, "Enabling Privacy Protection and Content Assurance in Geo-Social Networks", International Journal of Innovative Research in Management, Engineering and Technology, Vol 3, Issue 4, pp. 49-55, April 2018.

16. Dr. C. Rajabhushanam, V. Karthik, and G. Vivek, "Elasticity in Cloud Computing", International Journal of Innovative Research in Management, Engineering and Technology, Vol 3, Issue 4, pp. 104-111, April 2018.

17. K. Rangaswamy and Dr. C. Rajabhushanamc, "CCN-Based Congestion Control Mechanism In Dynamic Networks", International Journal of Innovative Research in Management, Engineering and Technology, Vol 3, Issue 4, pp. 117-119, April 2018.

18. Kavitha, R., Nedunchelian, R., "Domain-specific Search engine optimization using healthcare ontology and a neural network backpropagation approach", 2017, Research Journal of Biotechnology, Special Issue 2:157-166

19. Kavitha, G., Kavitha, R., "An analysis to improve throughput of high-power hubs in mobile ad hoc network" , 2016, Journal of Chemical and Pharmaceutical Sciences, Vol-9, Issue-2: 361-363

20. Kavitha, G., Kavitha, R., "Dipping interference to supplement throughput in MANET", 2016, Journal of Chemical and Pharmaceutical Sciences, Vol-9, Issue-2: 357-360

21. Michael, G., Chandrasekar, A.,"Leader election based malicious detection and response system in MANET using mechanism design approach", Journal of Chemical and Pharmaceutical Sciences(JCPS) Volume 9 Issue 2, April - June 2016.

22. Michael, G., Chandrasekar, A.,'Modeling of detection of camouflaging worm using epidemic dynamic model and power spectral density", Journal of Chemical and Pharmaceutical Sciences(JCPS) Volume 9 Issue 2, April - June 2016

23. Pothumani, S., Sriram, M., Sridhar, J., Arul Selvan, G., Secure mobile agents communication on intranet,Journal of Chemical and Pharmaceutical Sciences, volume 9, Issue 3, Pg No S32-S35, 2016

24. Pothumani, S., Sriram, M., Sridhar, Various schemes for database encryption-a survey, Journal of Chemical and Pharmaceutical Sciences, volume 9, Issue 3, Pg NoS103-S106, 2016

25. Pothumani, S., Sriram, M., Sridhar, A novel economic framework for cloud and grid computing, Journal of Chemical and Pharmaceutical Sciences, volume 9, Issue 3, Pg No S29-S31, 2016

26. Priya, N., Sridhar, J., Sriram, M. "Ecommerce Transaction Security Challenges and Prevention Methods- New Approach" 2016 ,Journal of Chemical and Pharmaceutical Sciences, JCPS Volume 9 Issue 3.page no:S66-S68 .

27. Priya, N.,Sridhar,J.,Sriram, M."Vehicular cloud computing security issues and solutions" Journal of Chemical and Pharmaceutical Sciences(JCPS) Volume 9 Issue 2, April - June 2016

28. Priya, N., Sridhar, J., Sriram, M. "Mobile large data storage security in cloud computing environment-a new approach" JCPS Volume 9 Issue 2. April - June 2016

29. Anuradha.C, Khanna.V, "Improving network performance and security in WSN using decentralized hypothesis testing "Journal of Chemical and Pharmaceutical Sciences(JCPS) Volume 9 Issue 2, April - June 2016.

\section{AUTHORS PROFILE}

P. Arumugam, Research Scholar, Department of CSE, Bharath Institute of Higher Education and Research, Chennai, Tamilnadu, India.

Dr.T. Krishna Kumar, Professor, Department of CSE, Bharath Institute of Higher Education and Research, Chennai, Tamilnadu, India. 